\title{
Gene-nutrient interactions during fetal development
}

\author{
Christopher A Maloney and William D Rees \\ The Rowett Research Institute, Greenburn Road, Bucksburn, Aberdeen, AB21 9SB, Scotland \\ Correspondence should be addressed to W D Rees; Email: W.Rees@rowett.ac.uk
}

\begin{abstract}
Eukaryotic cells have evolved a complex series of nutrient sensors that protect them from damage caused by acute deficiencies and also mediate adaptive responses to prolonged excess or deficiency of particular nutrients. In adults gene expression is regulated by nutrients interacting with pathways involving mammalian target of rapamycin (mTOR), CCAAT/ enhancer-binding proteins (C/EBPs) and peroxisome proliferator activator proteins (PPARs). These systems are also present in key cells of the developing oocyte, embryo and fetus. In this review we will consider the role of interactions between genes and nutrients during reproduction with a particular emphasis on their possible involvement in the prenatal programming of glucose metabolism in the adult.

Reproduction (2005) $130401-410$
\end{abstract}

\section{Introduction}

It has long been known that the maternal diet, and therefore the nutrient supply to the developing oocyte, embryo or fetus, is one of the principal environmental factors influencing the development of the offspring. A reliable and balanced supply of amino acids, lipids and carbohydrates is required to support the high rates of cell proliferation and the key developmental processes that take place during the embryonic (pre-implantation) and fetal (post-implantation) stages of life. Eukaryotic cells have evolved a complex series of nutrient sensors that are able to regulate gene expression in response to imbalances in the supply of nutrients. In adults these systems serve two purposes; firstly to protect the cell from damage caused by acute deficiencies and secondly to optimise homeostatic control to deal with a prolonged excess or deficiency of a particular nutrient. This second process may have a critical impact on the long term health of the offspring. It has been proposed that adverse nutritional conditions during fetal development lead to adaptive changes in metabolism that lead to a 'thrifty phenotype' in the offspring (Hales and Barker 1992). Poor nutrition in early life produces permanent changes in glucose-insulin metabolism, including a reduced capacity for insulin secretion and insulin resistance (Hales and Barker 2001). However, if this 'programming' of metabolism during embryonic and fetal development is inappropriate for the long term nutritional environment it may lead to adverse long term sequelae for the offspring (Sayer et al. 2004, Yajnik 2004, Barker 2004). The initiating factor(s) for fetal programming may be nutrient(s) interacting directly with genes and their regulatory elements at the cellular level, altering patterns of growth and gene expression. In this review we will concentrate on some of the direct interactions between genes and nutrients and their possible influence on fetal development.

\section{Interactions between nutrients and gene expression in cells}

The signals generated by growth factors and their receptors are modulated by macronutrient sensing pathways, which integrate developmental and environmental signals to regulate cellular growth and differentiation. Much of our understanding of these pathways has come from studies of cells in vitro and have been the subject of a number of excellent recent reviews (Ramji \& Foka 2002, Fingar \& Blenis 2004, Pegorier et al. 2004). Three interrelated systems change both the rate of mRNA translation and the transcription of genes in response to both transient and long-term imbalances in the nutrient supply (Fig 1).

\section{Nutrient sensing protein kinases}

The translation of mRNA into protein is regulated by a protein kinase known as the mammalian target of rapamycin (mTOR) which orchestrates an immediate response to disturbances in the amino acid or energy supply (Bruhat et al. 2002, Asnaghi et al. 2004). When amino acids, and in particular leucine, are plentiful mTOR forms a complex with other proteins to phosphorylate key components of the complex which translates mRNAs into proteins. These include the cap-binding initiation factor elF4E, the 


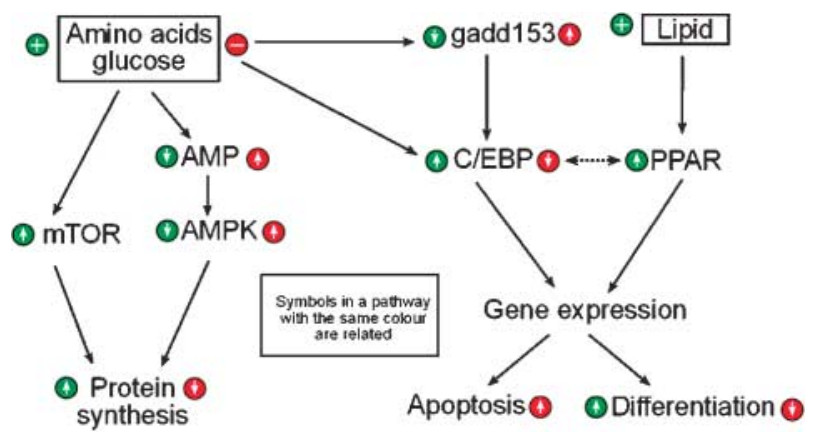

Figure 1 Mammalian cells possess three inter-related nutrient signalling systems that mediate the response to the availability of amino acids, glucose and lipids in the surrounding medium. Amino acid or glucose levels are sensed directly through the mTOR kinase or indirectly through the AMP activated kinase. Sufficient levels of these nutrients $(+)$ stimulate $\operatorname{mTOR}(\Uparrow)$ and activate protein synthesis $(\Uparrow)$. Conversely low levels of glucose and amino acids (-) increase intracellular AMP $(\Uparrow)$ activating the AMP dependent kinase which inhibits protein synthesis $(\Downarrow)$. The availability of glucose and amino acids also influences the gadd153 and C/EBP transcriptional activators through signals generated either by the accumulation of proteins in the endoplasmic reticulum or through the mTOR and AMPK kinases. When glucose and amino acids are low $(-)$ the levels of gadd153 mRNA rise $(\Uparrow)$ interfering with the normal action of C/EBP and changing patterns of gene expression. Lipids are sensed through binding to the PPAR subfamily of nuclear hormone receptors. Binding of ligands ( $\Uparrow$ ) increases PPAR activity inducing gene expression. Interactions between gadd153, C/EBP and PPAR transcription factors modulate gene expression in the cell determining whether a cell undergoes apoptosis or differentiation.

ribosomal protein S6 kinases (p70 S6 kinase), and elongation factor eEF2 (Fingar \& Blenis 2004, Hay \& Sonenberg 2004). Depletion of intracellular amino acid pools or removal of amino acids from the extracellular medium inhibits the mTOR kinase, suppressing protein synthesis. The absence of mTOR signalling also prevents the activation of cyclin dependent kinases (CDKs) and accelerates the turnover of cyclin D1, leading to a deficiency of active CDK4/cyclin D1 complexes, arresting cell growth in the G1-phase of the cell cycle (Panwalkar et al. 2004). The response to low glucose or hypoxia is regulated by a parallel protein kinase activated by increased intracellular AMP concentrations. A reduction in glycolysis or oxidative metabolism depletes intracellular ATP and increases AMP. The AMP activated protein kinase pathway senses this accumulation of AMP and inhibits the activation of p70 S6 kinase (Tokunaga et al. 2004, Meijer \& Dubbelhuis 2004). This pathway also exerts effects on transcriptional regulators responsible for mitochondrial biogenesis and lipid synthesis in adult tissues.

\section{Leucine zipper proteins}

Cells respond to nutrient deficiency with the appearance of mRNAs normally found at low levels in rapidly dividing cells. The CHOP-10/gadd153 (C/EBP homologous protein 10/growth arrest and DNA damage gene 153)
mRNA is upregulated within 4 hours of cells being exposed to media deficient in glucose, amino acids (Jousse et al. 2004) or other key components such as choline (van der Sanden et al. 2004). The expression of CHOP-10/gadd153 is regulated by the mTOR pathway (Entingh et al. 2001) and also by transcription factors from the activating transcription factor (ATF) family (Averous et al. 2004). The ATF-4 factors are produced in response to the accumulation of unfolded proteins in the endoplasmic reticulum through premature termination of the peptide chain, a failure of glycosylation or other defects in the export process. Unfolded proteins activate a series of protein kinases known as the unfolded protein response (UPR) (Zhang \& Kaufman 2004). These kinases phosphorylate the alpha subunit of translation initiation factor 2 (elF2-alpha), one of the proteins that control the binding of ribosomes to mRNA. Phosphorylation of elF2-alpha inhibits the translation of most mRNAs and suppresses total protein synthesis (Harding et al. 2000). However, some mRNAs, including that for the transcription factor ATF-4, are still able to associate with ribosomes. Therefore the UPR promotes translation of ATF-4 and stimulates CHOP-10/gadd153 transcription (Harding et al. 2003).

The product of the CHOP-10/gadd $153 \mathrm{mRNA}$ is a nuclear protein related to the CCAAT/enhancer-binding protein (C/EBP) family of transcription factors. All of these proteins have a leucine rich region (leucine zipper) and a DNA binding domain (Ramji and Foka 2002). Two C/EBP molecules bind together through the leucine zipper to form a dimer, which activates transcription from specific DNA sequences in the promoters of target genes. Homoand hetero- dimers of the C/EBP transcription factors are involved in a well characterised cascade of gene expression which leads to the terminal differentiation of a number of cell types including hepatocytes and adipocytes (Fig. 2) (Lane et al. 1999). One of the key components in this cascade is C/EBP-beta which is expressed during the process of cell commitment (Ramji and Foka 2002). When the CHOP-10/gadd153 protein is induced, it can form dimers with other members of the C/EBP family of transcription factors including C/EBP-beta. This disrupts the normal pattern of C/EBP-beta mediated gene transcription and initiates the expression of a new series of mRNAs (Wang et al. 1998). Under extreme circumstances the changes in gene expression mediated by $\mathrm{CHOP}$ 10/gadd153 leads to the death of the cell through apoptosis (Zinszner et al. 1998).

The C/EBP family of transcription factors are themselves subject to transcriptional regulation and postranslational modification by the nutrient supply. The UPR influences the C/EBP-beta mRNA levels through an element upstream of the promoter (Chen et al. 2004). In the liver several $\mathrm{N}$-terminally truncated isoforms of C/EBP-alpha and C/EBP-beta are produced by initiation of translation from alternative start sites. The C/EBP-beta protein occurs in three alternative translation products; the full length $35 \mathrm{kDa}$ protein, liver activating protein (LAP; a $32 \mathrm{kDa}$ 


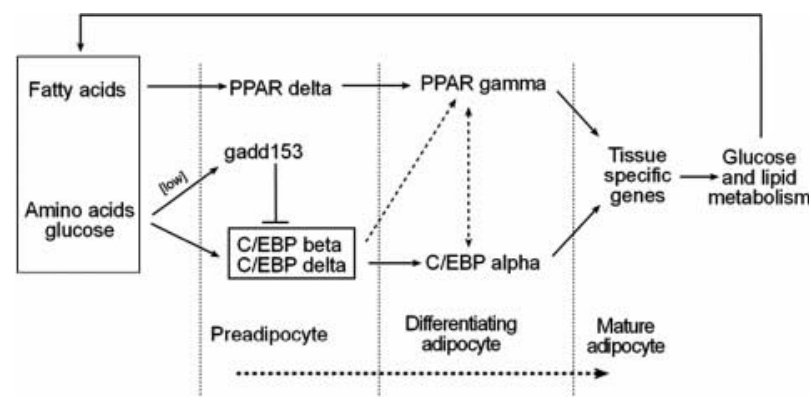

Figure 2 Temporal changes in nutrient sensitive gene expression during the differentiation of pre-adipocytes into mature adipocytes. Following the induction of cell differentiation the C/EBP and PPAR genes form a nutrient sensitive feedback loop to regulate the differentiation process. When fats are abundant long chain fatty acids interact with PPAR-delta and PPAR-gamma to promote adipogenesis. Similarly amino acids and glucose interact with C/EBP-delta and C/EBPbeta. Low levels of glucose induce gadd153, which forms inactive dimers with C/EBP-beta inhibiting the progress of adipocyte development. Interactions between the PPAR and C/EBP transcriptional activators (dotted lines) control the expression of tissue specific genes leading to and maintaining the mature phenotype. The numbers of mature adipocytes influence whole body glucose and lipid metabolism to create a feedback loop, which influences the subsequent differentiation of the next lineage of preadipose cells. Thus the availability of nutrients influences the development of adipose tissue depots. A similar feedback loop involving PPARs and C/EBPs also regulates the development of hepatocytes and pancreatic beta cells.

active isoform of C/EBP-beta) and liver inhibitory protein (LIP; a $20 \mathrm{kDa}$ inhibitory isoform of C/EBP-beta) (Descombes and Schibler 1991). LIP retains the leucine zipper but lacks the activation domain found in the active isoform LAP. In the adult prolonged hyperglycemia increases the LAP/LIP ratio and alters phosphoenol pyruvate carboxy kinase (PEPCK) expression (Shao et al. 2005). The function of C/EBP-beta is also regulated by a protease induced by C/EBP-alpha following terminal differentiation of cells. This protease generates a truncated form of the C/EBPbeta protein and represses the activity of the full length protein (Welm et al. 1999). This range of control mechanisms enables the C/EBP proteins to respond to nutrients and act in concert with other factors such as CHOP10/gadd153 or members of the peroxisome proliferatoractivated receptor (PPAR) family (described below) to modify the process of cell commitment and terminal differentiation.

\section{Nuclear hormone receptor super family}

Fatty acids and other lipophilic molecules control the expression of a network of target genes through interactions with members of the nuclear hormone receptor super family (Olefsky 2001). These receptors can be broadly categorised according to their ligands. For example, one family of these receptors, retinoic acid receptor (RAR) and retinoid $X$ receptor (RXR) bind retinoic acid (derived from vitamin $\mathrm{A}$ ) and play an essential role in regulating the differentiation of numerous cell types (Zile 2001). The nuclear receptor superfamily also includes receptors for thyroid hormones, vitamin $\mathrm{D}$ and liver $\mathrm{X}$ receptor (LXR). Another group of receptors from this family associated with cellular responses to fatty acids are the PPARs (Kota et al. 2005). These receptors modulate lipid and glucose metabolism by acting as transcriptional activators following the binding of fatty acids or fatty acid derived molecules such as prostaglandin J2 (Ferre 2004, Evans et al. 2004). The PPAR family comprises three isoforms that are expressed at different stages of development and in different tissues (van Bilsen et al. 2002). In the adult PPAR-alpha is expressed in liver, heart and muscle, PPAR-gamma is highly expressed in adipose tissue and the third isoform PPAR-delta (also known as PPAR-beta) is ubiquitously expressed in many tissues.

Members of the superfamily can form hetero-dimers with one another, thus for example; PPARs can form dimers with the retinoic acid receptors, the thyroid hormone receptor and the vitamin D receptor. Heterodimers of LXR/RXR play a particularly important role as the dominant activators of the sterol regulatory element-binding proteins (SREBPs). These membrane-bound transcription factors from the basic helix-loop-helix leucine zipper family are highly expressed in liver and adipose tissue where they are key regulators of cholesterol and fatty acid synthesis (Yoshikawa et al. 2001, Yoshikawa et al. 2003). In adults the SREBP-1c isoform responds to dietary glucose and controls hepatic lipogenesis through its close links to the signalling cascade downstream of the insulin receptor (Osborne 2000). Another isoform, SREBP-2 is a key regulator of cholesterol biosynthesis. Through their impact on factors such as SREBPs the nuclear hormone receptors are essential in the nutrient mediated regulation of lipid metabolism.

The nuclear receptors share common structural motifs, which includes areas for DNA recognition, ligand binding and cofactor interactions. The DNA recognition domain binds to specific nucleotide response elements in enhancer or promoter regions of the target genes and is able to activate transcription after ligand binding (Privalsky 2004). The co-factor binding sites enable the dimers to form complexes with co-repressor proteins which catalyse post-translational modifications of histones and other proteins to maintain the local chromatin structure and facilitate gene transcription. These modifications of chromatin may be an important factor in prenatal metabolic programming.

\section{Gene nutrient interactions during development}

Human and animal studies suggest that the developing fetus is susceptible to metabolic programming throughout gestation. Imbalances in the nutrient supply induce both responsive and adaptive changes in development. The mTOR kinase has a central role in responding to adverse environmental conditions, protecting cells by regulating 
protein synthesis. Under more extreme conditions induction of CHOP-10/gadd153 invokes stress responses to eliminate damaged cells through apoptosis. The C/EBP and PPAR factors play a more adaptive role during tissue development. By sensing the availability of carbohydrate and lipids these factors regulate differentiation of progenitor cells, adapting tissue development in response to the nutrient supply. Studies of animals with specific defects suggest that both the stress response and adaptive responses to nutrients are essential in the normal development of key cell types involved in metabolic homeostasis. A number of potential mechanisms for the long term programming of metabolism involving the direct effects of nutrients on gene expression are becoming apparent. Current experimental data support each of these mechanisms, however it does not preclude the possibility that they may all be operating as part of a combined process which ultimately leads to the programming of metabolism in the offspring.

\section{Changes in the growth of the developing oocyte or embryo}

Disturbances in pre-implantation development have been reported to produce a number of different phenotypes including obesity (Sjoblom et al. 2005) and hypertension (Kwong et al. 2000) in the offspring. Disrupting the growth of the embryo in vivo prior to implantation modifies cell allocation in the blastocyst (Fleming et al. 2004). Embryo culture in vitro is also reported to restrict fetal growth and modify placental morphogenesis (Sjoblom et al. 2005). These studies suggest that suboptimal pre-implantation or early post-implantation growth alter the ratio of placental to fetal tissue mass. Perturbation of early placental growth cannot be reversed, permanently compromising the nutrient supply to developing fetus. Studies of embryo development in vitro and subsequent embryo transfer have shown that early development is dependent on a number of different factors, including oocyte maturation and blastocyst growth.

\section{Oocyte maturation}

The early stages of development post-fertilisation depend on the quality of the oocyte. Data from oocytes matured in vitro suggests that several nutritional and endocrine factors influence follicle development (Rodriguez \& Farin 2004). In particular the successful maturation of the oocyte is critically dependent on interactions with the surrounding granulosa cells (Kim et al. 1997). There is evidence that mTOR, C/EBPs and PPARs are all involved in regulating granulosa cell function. These may provide a mechanism to suppress ovulation in response to severe nutritional imbalances such as those induced by famine or anorexia. However, it is also possible that inappropriate oocyte maturation may lead to subtle changes in post-fertilisation development.
Cell proliferation following stimulation with follicle stimulating hormone is dependent on the mTOR pathway to promote the phosphoinositol 3-kinase-dependent activation of p70 S6 kinase (Alam et al. 2004). In addition to $\mathrm{mTOR}$, follicular differentiation is also dependent on the C/EBP transcription factors. Deletion of the C/EBP-beta gene leads to failure of follicular development as the granulosa cells are unable to respond to luteinising hormone (Sterneck et al. 1997). There is also an important role for C/EBP-alpha and C/EBP-beta during the transition period from follicle to corpus luteum (Gillio-Meina et al. 2005). The mRNA of all three PPAR isoforms is expressed in the rat ovary, with PPAR-gamma the principal form found in the granulosa cells. Mice with a targeted deletion of the PPAR-gamma gene in oocytes and granulosa cells had a normal population of follicles, were able to ovulate and develop corpora lutea (Cui et al. 2002). This suggests that PPAR-gamma is not essential for follicular functions, however, the animals had a reduced implantation rate. It has been suggested that PPAR-gamma plays a part in regulating oocyte maturation by acting as a negative regulator of follicular growth and differentiation (Lovekamp-Swan \& Chaffin 2005). All of these studies demonstrate that granulosa cells possess mechanisms to regulate oocyte maturation in response to the nutritional environment. However, at present it is not clear if changes in the maternal diet can modify oocyte maturation through these gene nutrient interactions.

\section{Blastocyst growth}

Mouse blastocyst outgrowth in vitro and probably implantation in vivo require amino acid signalling via the mTOR pathway. The presence of amino acids, and particularly leucine, in the extracellular medium stimulates mTOR activity in the blastocyst, suggesting that this pathway regulates blastocyst growth and implantation in response to the amino acid supply (Martin et al. 2003). When the kinase domain of mTOR is disrupted by homologous recombination, homozygous mutant embryos die shortly after implantation due to impaired cell proliferation showing that this is a critical developmental checkpoint for implantation (Gangloff et al. 2004, Murakami et al. 2004).

Prolonged exposure to genotoxic stress (and probably amino acid deficiency) induces the CHOP10/gadd153 mRNA and initiates apoptosis in the blastocyst (Fontanier-Razzaq et al. 2001). This response to nutritional and environmental stress probably removes damaged cells and prevents them from proliferating through the developing fetus. The C/EBP transcription factors appear to become important following implantation where they are expressed alongside the CHOP10/gadd153 mRNA during placental development. Mouse embryos with targeted deletions of both C/EBP-alpha and C/EBP-beta die between embryonic days 10 and 11 because of defects in the labyrinth layer of their placentas (Begay et al. 2004). However, a single copy of either 
C/EBP-beta, or C/EBP-alpha is sufficient to support development. This suggests that although both transcription factors function during early embryonic development there is a degree of redundancy. A targeted deletion of the PPARgamma gene also affects the ability to establish a labyrinth layer in the placenta (Asami-Miyagishi et al. 2004). The placenta acts as the interface between the fetus and the maternal circulation where it serves an important role in regulating fetal nutrient supply. These studies of animals with targeted deletions suggest that the C/EBP proteins regulate placental development in concert with PPARs. However, it is not known to what degree these nutrient sensitive genes have a physiological role in buffering and adapting placental development to optimise the nutrient supply to the developing fetus.

\section{Epigenetic modifications of chromatin structure}

A number of disease states in humans are the result of subtle changes in gene expression caused by alterations in chromatin structure (epigenetic modifications; Robertson \& Wolffe 2000). Epigenetic marks such as the covalent methylation of cytosine residues in DNA are set in the chromatin during development and determine the accessibility of a particular gene to the transcriptional machinery (Spiegelman \& Heinrich 2004). By regulating gene expression through changes in the promoter region, these epigenetic modifications represent another mechanism for the nutritional regulation of gene expression.

Epigenetic modifications may result from the direct effects of changes in metabolism as the process of chromatin remodelling depends on a number of products derived from intermediary metabolism such as S-adenosyl methionine (SAM), acetyl CoA and nicotinamide adenine dinucleotide $\left(\mathrm{NAD}^{(+)}\right)$. The modification of cytosine residues with methyl groups derived from SAM serves two purposes, transcriptional repression and genome defence (Grace Goll \& Bestor 2005). There is a growing body of evidence showing that transcriptional repression and genome defence is perturbed by changes in metabolism. Embryo culture techniques in farm animals frequently expose the preimplantation embryo to an inappropriate nutritional environment in vitro, leading to defective epigenetic programming and a number of developmental abnormalities collectively known as the large offspring syndrome (Young et al. 2001). Studies have revealed that the expression of a number of key genes is altered in these large offspring (Young \& Beaujean 2004). Defects in epigenetic programming can also affect metabolism, the surviving offspring of mice produced by nuclear transfer (where the transferred nucleus undergoes extensive epigenetic reprogramming) exhibit an obese phenotype (Tamashiro et al. 2002). Many of the cytosine residues modified by methylation reside within parasitic DNA elements or retrotransposons, such as endogenous retroviruses. One of the best-studied examples is the Agouti mouse (Wolff et al. 1998). In this animal an endogenous retrovirus-like transposon sequence is inserted close to the gene coding for the Agouti protein. Normally a cryptic promoter within the retrotransposon is silenced by methylation allowing normal tissue-specific and regulated agouti expression. However, if this site is undermethylated the promoter is active and drives constitutive ectopic expression of the agouti gene, leading to yellow coat colour and obesity. It has been shown that the methylation status of these inserted viral DNA sequences can be modified by the methionine, folic acid and choline content of the maternal diet, illustrating that the extent of methylation is determined by events occurring in utero (Cooney et al. 2002). Adding additional methyl donors to the maternal diet increases methylation of the retrotransposon, suppresses ectopic gene expression and improves the outcome for the offspring. However, the wider relevance of this model still unclear and it is not known whether nutritional regulation of similar retrotransposon sequences is responsible for disease in humans.

The methylation of cytosine bases in DNA is tightly associated with modification of histone tails and other changes in chromosome structure (reviewed by Santos \& Dean 2004). DNA is assembled on core histones; the tails of which are exposed on the nucleosome surface, where they are subject to a variety of enzyme-catalysed, posttranslational modifications. The acetylation and methylation of histones, mediated by histone acetyl transferases and histone methyl transferases, changes the structure of the nucleosome and allows other proteins access to the DNA (Hermanson et al. 2002). A group of histone deacetylases reverses the acetylation of histones in a reaction that requires $\mathrm{NAD}^{(+)}$(Blander \& Guarente 2004). These processes are essential for the differentiation of cells such as hepatocytes and adipocytes. It has been suggested that methylation and acetylation of histones introduces a 'histone code' which acts as a form of cellular memory influencing the subsequent binding and therefore function of transcriptional activators responsible for the differentiated phenotype (Turner 2002).

Chromatin remodelling is particularly important in the oocyte and early embryo. In these cells the pattern of coactivator expression is different from that observed in somatic cells, reflecting the specialised events occurring during early development (Zheng et al. 2005). In particular the modification of chromatin with poly ADP-ribose (derived from $\mathrm{NAD}^{(+)}$) is essential for normal preimplantation development (Imamura et al. 2004). It is interesting to speculate that this requirement for $\mathrm{NAD}^{(+)}$during the early stages of development may be associated with the dependence of the pre-implantation embryo on pyruvate metabolism (Houghton \& Leese 2004). The $\mathrm{NAD}^{(+)}$ dependent deacetylases are also essential during the later stages of fetal development where loss of activity leads to reduced fetal growth and defects in the lung and pancreas (McBurney et al. 2003). In the liver of rat fetuses, the nutritional stresses produced by uteroplacental insufficiency produce specific changes in the association of 
acetylated histones with the promoters of genes dependent on PPAR (Fu et al. 2004). Nutrient sensitive transcriptional activators, such as the C/EBPs and PPARs, are able to determine local chromatin structure through interactions with co-activator proteins. This provides a second indirect route for nutritionally mediated epigenetic programming of gene expression (Jia et al. 2004).

\section{Post-implantation development and organogenesis}

After implantation a number of discrete metabolic compartments are established within the fetus as the organs are formed. The feedback loops that regulate adult metabolism begin to develop during this period, presenting another opportunity for developmental programming. In the case of the insulin axis this involves the beta-cells of the pancreas which produce insulin and the insulin sensitive tissues which include the liver, muscle and adipose tissue (Fig 3). Key roles for mTOR, C/EBP and PPARs have been described in the development of tissues involved in maintaining metabolic homeostasis and in the adaptive response of adult animals to obesogenic diets. However less is known about the role of these gene nutrient interactions during fetal development.

Cells of the liver and pancreas originate from a common pool of progenitor cells in the ventral foregut endoderm. This close relationship is not surprising, as these tissues are responsible for processing the nutrients from ingested food and maintaining lipid and glucose concentrations in the blood. The proliferation of adult pancreatic beta cells is mediated by physiological concentrations of leucine and glucose in vitro. These nutrients stimulate the mTOR pathway which increases p70 S6 kinase phosphorylation (Xu et al. 2001) and DNA synthesis (Kwon et al. 2004). The mTOR pathway also plays a key role in regulating the proliferation of primary hepatocyte cultures (Coutant et al. 2002). However, studies of fetal livers during late gestation suggests that proliferation may be mTOR and insulin independent (Anand et al. 2002). Therefore the role of this signalling pathway during fetal development of both pancreas and liver remains unclear.

In contrast there is evidence that mTOR is involved in the regulation of fetal muscle development. In the adult, muscle is one of the main organs involved in the clearance of glucose and amino acids from the circulation and thus changes in muscle mass or insulin sensitivity greatly affect whole body glucose metabolism. For example, in sheep the development of muscles and skeleton was retarded in fetuses of nutrient-restricted ewes. The levels of $\mathrm{mTOR}$ and ribosomal protein S6 proteins were unchanged, but the phosphorylation of both proteins was reduced in muscle from nutrient-restricted fetuses. It is possible that the decrease in mTOR signalling reduces myoblast proliferation and reduces the number of secondary myofibers (Zhu et al. 2004).

The CHOP-10/gadd153 gene is not essential for the process of organogenesis as animals with a targeted deletion of the gene develop normally. This is despite it being widely expressed in fetal tissues. Data from adult animals show that the unfolded protein response, mediated though CHOP-10/gadd153, is important in regulating the apoptosis of beta cells (Oyadomari et al. 2002). The presence of misfolded insulin molecules induces the unfolded protein response (UPR) in the beta cell and leads to its destruction by apoptosis. These data suggest that this pathway is concerned with the response to stress rather than normal development. It will be interesting to see if animals with targeted deletions of CHOP-10/gadd153 show abnormal fetal development when they are exposed to nutritional stresses during gestation.

The CHOP-10/gadd153 and C/EBP genes play a pivotal role in the differentiation and final maturation of the beta cells, hepatocytes and adipocytes in vitro (Fig 2). Studies of animals with targeted deletions of the C/EBP alpha gene show that it is not essential for the morphological development of the liver in vivo. However the expression of $\mathrm{C} / \mathrm{EBP}$-alpha is required for the expression of genes involved in the normal metabolic functions of adult liver. Animals lacking C/EBP-alpha do not express glycogen synthase and die at the neonatal stage due to hypoglycaemia (Ramji \& Foka 2002). In contrast deletion of the C/EBP-beta gene leads to early embryonic lethality because it is required for the development of the placenta. The C/EBP-beta gene also plays an important part in the

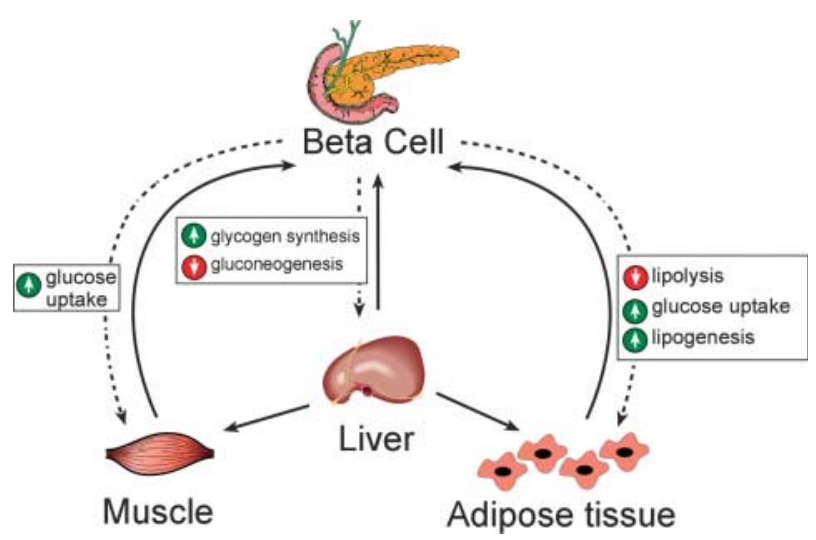

Figure 3 The feedback loops of the insulin axis involve a number of different tissues. These tissues learn to communicate with each other during the late fetal and early postnatal stages of development. Signalling from the beta cells of the pancreas is via insulin (dotted lines). This acts on liver, muscle and adipose tissue to change levels of glucose in the circulation (solid lines). The development of liver, muscle and adipose tissue is regulated by gene nutrient interactions. If the nutritional balance is perturbed by changes in the maternal diet, the development of tissues is also changed altering the characteristics of this feedback loop. The communication between these organs is a complex web where subtle changes in just one component can influence the behaviour of the whole system. For example, decreased maternal nutrition may suppress beta cell development resulting in fewer fetal beta cells, resulting in reduced insulin release, requiring a corresponding increase in insulin sensitivity of fetal liver, muscle or adipose tissue to maintain glucose homeostasis. 
regulation of islet development (Lu et al. 1997). Analysis of C/EBP expression in the livers of fetuses exposed to a low protein diet fail to show any changes either in C/EBP or CHOP-10/gadd153 mRNA levels suggesting that maternal protein deficiency does not influence transcription (Maloney et al. 2005). However, other nutritional imbalances, e.g. hyperglycaemia, may induce different patterns of metabolic stress which lead to changes in CHOP-10/gadd153 expression or to changes in the C/EBP isoforms.

The role of PPARs in modulating the insulin axis has been highlighted by the development of pharmacological agonists for these receptors. Treatment with PPAR-gamma agonists improves whole body insulin sensitivity by redirecting lipid from non-adipose tissue towards adipocytes. This is accomplished by altering the expression of genes involved in lipid metabolism such as the aP2 fatty acid binding protein, the CD36 lipoprotein receptor, lipoprotein lipase as well as adipose signalling molecules such as leptin and resistin. In adults fed a high fat diet PPAR-alpha modulates islet insulin secretion and it has been suggested that it may act as a general sensor of overall tissue lipid supply (Sugden \& Holness 2004). Animals with a targeted deletion of PPAR-alpha are fertile but adults have severe metabolic defects suggesting that PPAR-alpha plays a role later in development. In contrast deletion of the PPARgamma gene is lethal because the placenta fails to develop. When these embryos are rescued by forming chimeras, embryos with a deletion of PPAR-gamma survived showing that expression is not essential for organogenesis. However, the offspring are devoid of adipose tissue and die soon after birth (Barak et al. 1999). A targeted deletion of PPARgamma in the beta cells leads to islet hyperplasia in mice, however, the increase in islet mass in response to high-fat feeding does not occur (Rosen et al. 2003). Analysis of PPAR gene expression in the liver suggests that the expression of these mRNAs is low during the embryonic period (Balasubramaniyan et al. 2005). It will be interesting to see if nutritional imbalances, such as those induced by feeding high fat diets during gestation have any impact on gene expression.

The gene deletion experiments highlight the essential role of PPAR-gamma in adipogenesis. During development immature pre-adipocytes are held in an undifferentiated state through inhibition of C/EBP and PPAR expression by Wnt signalling (Ross et al. 2000, Bennett et al. 2002). In response to adipogenic stimuli pre adipose cells express C/EBP-beta and PPAR-delta. These transcriptional activators in turn initiate the expression of PPARgamma and C/EBP-alpha which then transcribe the genes involved in creating the complete adipocyte phenotype. Adipogenesis is controlled by a positive feedback loop, which is sensitive to long-chain, saturated, and polyunsaturated fatty acids through PPAR-gamma and to glucose through CHOP-10/gadd153 and C/EBP. Although this system is well understood in the adult there is little information on the regulation of adipogenesis during fetal development. The proliferation and differentiation of pre- adipocytes isolated from rat fetuses is not sensitive to the level of protein in the maternal diet (Bieswal et al. 2004). The available evidence suggests that changes in adiposity and fat deposition in animal models result from a change in the endocrine environment of the offspring. However, these studies do not rule out the possibility of changes in the numbers of pre adipose cells available for differentiation through the regulation of C/EBP and PPAR function.

\section{Conclusions}

It is becoming apparent that embryonic and fetal cells have a complex system to integrate nutritional signals from their environment and adapt their development accordingly to ensure survival. Human diets are comprised of complex mixtures of protein, fats, carbohydrate and vitamins. The full impact of inappropriate programming of metabolic regulation is only just beginning to be appreciated. The available evidence suggests that nutrient sensing regulatory systems are present in many critical tissues during early development. It remains to be seen whether they play an important part in establishing homeostatic control mechanisms early in life.

\section{Acknowledgements}

This work was supported by the Scottish Executive Environment and Rural Affairs Department as part of the core funding of the Rowett Research Institute. Christopher Maloney is supported by a cooperative agreement from the NIH (U01 HD044638 to Kevin Sinclair) as a component of the NICHD Cooperative Program on Female Health and Egg Quality. The authors thank Dr Jacqueline Wallace for critically reviewing the manuscript. The authors declare that there is no conflict of interest that would prejudice the impartiality of this scientific work.

\section{References}

Alam H, Maizels ET, Park Y, Ghaey S, Feiger ZJ, Chandel NS \& Hunzicker-Dunn M 2004 Follicle-stimulating hormone activation of hypoxia-inducible factor-1 by the phosphatidylinositol 3-kinase/AKT/Ras homolog enriched in brain Rheb/mammalian target of rapamycin mTOR pathway is necessary for induction of select protein markers of follicular differentiation. Journal of Biological Chemistry 279 19431-19440.

Anand P, Boylan JM, Ou Y \& Gruppuso PA 2002 Insulin signaling during perinatal liver development in the rat. American Journal of Physiology, Endocrinology and Metabolism 283 E844-E852.

Asami-Miyagishi R, Iseki S, Usui M, Uchida K, Kubo H \& Morita I 2004 Expression and function of PPARgamma in rat placental development. Biochemical and Biophysical Research Communications 315 497-501.

Asnaghi L, Bruno P, Priulla M \& Nicolin A 2004 mTOR: a protein kinase switching between life and death. Pharmacology Research 50 545-549.

Averous J, Bruhat A, Jousse C, Carraro V, Thiel G \& Fafournoux P 2004 Induction of CHOP expression by amino acid limitation requires both ATF4 expression and ATF2 phosphorylation. Journal of Biological Chemistry 279 5288-5297. 
Balasubramaniyan N, Shahid M, Suchy FJ \& Ananthanarayanan M 2005 Multiple mechanisms of ontogenic regulation of nuclear receptors during rat liver development. American Journal of Physiology, Gastrointestinal and Liver Physiology 288 G251-G260.

Barak Y, Nelson MC, Ong ES, Jones YZ, Ruiz-Lozano P, Chien KR, Koder A \& Evans RM 1999 PPAR gamma is required for placental, cardiac, and adipose tissue development. Molecular Cell $\mathbf{4}$ 585-595.

Barker DJ 2004 The developmental origins of chronic adult disease. Acta Paediatrica Supplement 93 26-33.

Begay V, Smink J \& Leutz A 2004 Essential requirement of CCAAT/enhancer binding proteins in embryogenesis. Molecular and Cellular Biology 24 9744-9751.

Bennett CN, Ross SE, Longo KA, Bajnok L, Hemati N, Johnson KW, Harrison SD \& MacDougald OA 2002 Regulation of Wnt signaling during adipogenesis. Journal of Biological Chemistry 277 30998-31004.

Bieswal F, Hay SM, McKinnon C, Reusens B, Cuignet M, Rees WD \& Remacle C 2004 Prenatal protein restriction does not affect the proliferation and differentiation of rat pre-adipocytes. Journal of Nutrition 134 1493-1499.

Blander G \& Guarente L 2004 The Sir2 family of protein deacetylases. Annual Reviews in Biochemistry 73 417-435.

Bruhat A, Averous J, Carraro V, Zhong C, Reimold AM, Kilberg MS \& Fafournoux P 2002 Differences in the molecular mechanisms involved in the transcriptional activation of the CHOP and asparagine synthetase genes in response to amino acid deprivation or activation of the unfolded protein response. Journal of Biological Chemistry 277 48107-48114.

Chen H, Pan YX, Dudenhausen EE \& Kilberg MS 2004 Amino acid deprivation induces the transcription rate of the human asparagine synthetase gene through a timed program of expression and promoter binding of nutrient-responsive basic region/leucine zipper transcription factors as well as localized histone acetylation. Journal of Biological Chemistry 279 50829-50839.

Cooney CA, Dave AA \& Wolff GL 2002 Maternal methyl supplements in mice affect epigenetic variation and DNA methylation of offspring. Journal of Nutrition 132 2393S-2400S.

Coutant A, Rescan C, Gilot D, Loyer P, Guguen-Guillouzo C \& Baffet G 2002 PI3K-FRAP/mTOR pathway is critical for hepatocyte proliferation whereas MEK/ERK supports both proliferation and survival. Hepatology 36 1079-1088.

Cui Y, Miyoshi K, Claudio E, Siebenlist UK, Gonzalez FJ, Flaws J, Wagner KU \& Hennighausen L 2002 Loss of the peroxisome proliferation-activated receptor gamma PPARgamma does not affect mammary development and propensity for tumor formation but leads to reduced fertility. Journal of Biological Chemistry 277 $17830-17835$.

Descombes P \& Schibler U 1991 A liver-enriched transcriptional activator protein, LAP, and a transcriptional inhibitory protein, LIP, are translated from the same mRNA. Cell 67 569-579.

Entingh AJ, Law BK \& Moses HL 2001 Induction of the C/EBP homologous protein CHOP by amino acid deprivation requires insulinlike growth factor I, phosphatidylinositol 3-kinase, and mammalian target of rapamycin signaling. Endocrinology 142 $221-228$.

Evans RM, Barish GD \& Wang YX 2004 PPARs and the complex journey to obesity. Nature Medicine 10 355-361.

Ferre P 2004 The biology of peroxisome proliferator-activated receptors: relationship with lipid metabolism and insulin sensitivity. Diabetes 53 Suppl 1 S43-S50.

Fingar DC \& Blenis J 2004 Target of rapamycin TOR: an integrator of nutrient and growth factor signals and coordinator of cell growth and cell cycle progression. Oncogene 23 3151-3171.

Fleming TP, Kwong WY, Porter R, Ursell E, Fesenko I, Wilkins A, Miller DJ, Watkins AJ \& Eckert JJ 2004 The embryo and its future. Biology of Reproduction 71 1046-1054.

Fontanier-Razzaq N, McEvoy TG, Robinson JJ \& Rees WD 2001 DNA damaging agents increase gadd153 CHOP-10 messenger
RNA levels in bovine preimplantation embryos cultured in vitro. Biology of Reproduction 64 1386-1391.

Fu Q, McKnight RA, Yu X, Wang L, Callaway CW \& Lane RH 2004 Uteroplacental insufficiency induces site-specific changes in histone $\mathrm{H} 3$ covalent modifications and affects DNA-histone $\mathrm{H} 3$ positioning in day 0 IUGR rat liver. Physiological Genomics 20 $108-116$.

Gangloff YG, Mueller M, Dann SG, Svoboda P, Sticker M, Spetz JF, Um SH, Brown EJ, Cereghini S, Thomas G \& Kozma SC 2004 Disruption of the mouse mTOR gene leads to early postimplantation lethality and prohibits embryonic stem cell development. Molecular and Cellular Biology 24 9508-9516.

Gillio-Meina C, Hui YY \& Lavoie HA 2005 Expression of CCAAT/Enhancer Binding Proteins Alpha and Beta in the Porcine Ovary and Regulation in Primary Cultures of Granulosa Cells. Biology of Reproduction 72 1194-1204.

Grace Goll M \& Bestor TH 2005 Eukaryotic cytosine methyltransferases. Annual Review of Biochemistry 74 481-514.

Hales CN \& Barker DJ 1992 Type 2 non-insulin-dependent diabetes mellitus: the thrifty phenotype hypothesis. Diabetologia 35 $595-601$

Hales CN \& Barker DJ 2001 The thrifty phenotype hypothesis. British Medical Bulletin. 60 5-20.

Harding HP, Novoa I, Zhang Y, Zeng H, Wek R, Schapira M \& Ron D 2000 Regulated translation initiation controls stressinduced gene expression in mammalian cells. Molecular Cell 6 1099-1108.

Harding HP, Zhang Y, Zeng H, Novoa I, Lu PD, Calfon M, Sadri N, Yun C, Popko B, Paules R, StojdI DF, Bell JC, Hettmann T, Leiden JM \& Ron D 2003 An integrated stress response regulates amino acid metabolism and resistance to oxidative stress. Molecular Cell 11 619-633.

Hay N \& Sonenberg N 2004 Upstream and downstream of mTOR. Genes \& Development 18 1926-1945.

Hermanson O, Glass CK \& Rosenfeld MG 2002 Nuclear receptor coregulators: multiple modes of modification. Trends in Endocrinology and Metabolism 13 55-60.

Houghton FD \& Leese HJ 2004 Metabolism and developmental competence of the preimplantation embryo. European Journal of Obstetrics, Gynecology and Reproductive Biology 115 Suppl 1 S92-S96.

Imamura T, Neildez TM, Thenevin C \& Paldi A 2004 Essential role for poly ADP-ribosylation in mouse preimplantation development. BMC Molecular Biology 54.

Jia Y, Qi C, Kashireddi P, Surapureddi S, Zhu YJ, Rao MS, Le Roith D, Chambon P, Gonzalez FJ \& Reddy JK 2004 Transcription Coactivator PBP, the Peroxisome Proliferator-activated Receptor PPARbinding Protein, Is Required for PPAR\{alpha\}-regulated Gene Expression in Liver. Journal of Biological Chemistry 279 $24427-24434$.

Jousse C, Averous J, Bruhat A, Carraro V, Mordier S \& Fafournoux P 2004 Amino acids as regulators of gene expression: molecular mechanisms. Biochemical and Biophysical Research Communications 313 447-452.

Kim KS, Minami N, Yamada M \& Utsumi K 1997 Follicular cells affect the fertilizability and developmental competency of bovine oocytes in vitro. Reproduction, Fertility and Development 9 $763-766$

Kota BP, Huang TH-W \& Roufogalis BD 2005 An overview on biological mechanisms of PPARs. Pharmacological Research 51 85-94.

Kwon G, Marshall CA, Pappan KL, Remedi MS \& McDaniel ML 2004 Signaling elements involved in the metabolic regulation of mTOR by nutrients, incretins, and growth factors in islets. Diabetes $\mathbf{5 3}$ Suppl 3 S225-S232.

Kwong WY, Wild AE, Roberts P, Willis AC \& Fleming TP 2000 Maternal undernutrition during the preimplantation period of rat development causes blastocyst abnormalities and programming of postnatal hypertension. Development 127 4195-4202. 
Lane MD, Tang QQ \& Jiang MS 1999 Role of the CCAAT enhancer binding proteins C/EBPs in adipocyte differentiation. Biochemical and Biophysical Research Communications 266 677-683.

Lovekamp-Swan T \& Chaffin CL 2005 The peroxisome proliferatoractivated receptor gamma ligand troglitazone induces apoptosis and p53 in rat granulosa cells. Molecular and Cellular Endocrinology 233 15-24.

Lu M, Seufert J \& Habener JF 1997 Pancreatic beta-cell-specific repression of insulin gene transcription by CCAAT/enhancer-binding protein beta. Inhibitory interactions with basic helix-loop-helix transcription factor E47. Journal of Biological Chemistry 272 28349-28359.

Maloney CA, Lilley C, Cruickshank MA, McKinnon C, Hay SM \& Rees WD 2005 The expression of growth arrest genes in the liver and kidney of the protein restricted rat fetus. British Journal of Nutrition 94 12-18.

Martin PM, Sutherland AE \& Van Winkle LJ 2003 Amino acid transport regulates blastocyst implantation. Biology of Reproduction 69 1101-1108.

McBurney MW, Yang X, Jardine K, Hixon M, Boekelheide K, Webb JR, Lansdorp PM \& Lemieux M 2003 The mammalian SIR2alpha protein has a role in embryogenesis and gametogenesis. Molecular and Cellular Biology 23 38-54.

Meijer AJ \& Dubbelhuis PF 2004 Amino acid signalling and the integration of metabolism. Biochemical and Biophysical Research Communications 313 397-403.

Murakami M, Ichisaka T, Maeda M, Oshiro N, Hara K, Edenhofer F, Kiyama H, Yonezawa K \& Yamanaka S 2004 mTOR is essential for growth and proliferation in early mouse embryos and embryonic stem cells. Molecular and Cellular Biology 24 6710-6718.

Olefsky JM 2001 Nuclear Receptor Minireview Series. Journal of Biological Chemistry 276 36863-36864.

Osborne TF 2000 Sterol regulatory element-binding proteins SREBPs: key regulators of nutritional homeostasis and insulin action. Journal of Biological Chemistry 275 32379-32382.

Oyadomari S, Koizumi A, Takeda K, Gotoh T, Akira S, Araki E \& Mori M 2002 Targeted disruption of the Chop gene delays endoplasmic reticulum stress-mediated diabetes. Journal of Clinical Investigation $109525-532$

Panwalkar A, Verstovsek S \& Giles FJ 2004 Mammalian target of rapamycin inhibition as therapy for hematologic malignancies. Cancer 100 657-666.

Pegorier JP, May CL \& Girard J 2004 Control of Gene Expression by Fatty Acids. Journal of Nutrition 134 2444S-22449.

Privalsky ML 2004 The Role of Corepressors in Transcriptional Regulation by Nuclear Hormone Receptors. Annual Review of Physiology 66 315-360.

Ramji DP \& Foka P 2002 CCAAT/enhancer-binding proteins: structure, function and regulation. Biochemical Journal 365 561-575.

Robertson KD \& Wolffe AP 2000 DNA methylation in health and disease. Nature Reviews Genetics 11-19.

Rodriguez KF \& Farin CE 2004 Gene transcription and regulation of oocyte maturation. Reproduction, Fertility and Development. 16 $55-67$.

Rosen ED, Kulkarni RN, Sarraf P, Ozcan U, Okada T, Hsu CH, Eisenman D, Magnuson MA, Gonzalez FJ, Kahn CR \& Spiegelman BM 2003 Targeted elimination of peroxisome proliferator-activated receptor gamma in beta cells leads to abnormalities in islet mass without compromising glucose homeostasis. Molecular and Cellular Biology 23 7222-7229.

Ross SE, Hemati N, Longo KA, Bennett CN, Lucas PC, Erickson RL \& MacDougald OA 2000 Inhibition of adipogenesis by Wnt signaling. Science 289 950-953.

Santos F \& Dean W 2004 Epigenetic reprogramming during early development in mammals. Reproduction 127 643-651.

Sayer AA, Syddall HE, Dennison EM, Gilbody HJ, Duggleby SL, Cooper C, Barker DJ \& Phillips DI 2004 Birth weight, weight at 1 $y$ of age, and body composition in older men: findings from the
Hertfordshire Cohort Study. Amican Journal of Clinical Nutrition 80 199-203.

Shao J, Qiao L, Janssen RC, Pagliassotti M \& Friedman JE 2005 Chronic Hyperglycemia Enhances PEPCK Gene Expression and Hepatocellular Glucose Production Via Elevated Liver Activating Protein/Liver Inhibitory Protein Ratio. Diabetes 54 976-984.

Sjoblom C, Roberts CT, Wikland M \& Robertson SA 2005 GM-CSF alleviates adverse consequences of embryo culture on fetal growth trajectory and placental morphogenesis. Endocrinology 146 $2142-2153$

Spiegelman BM \& Heinrich R 2004 Biological control through regulated transcriptional coactivators. Cell 119 157-167.

Sterneck E, Tessarollo L \& Johnson PF 1997 An essential role for C/EBPbeta in female reproduction. Genes \& Development 11 $2153-2162$

Sugden MC \& Holness MJ 2004 Potential role of peroxisome proliferator-activated receptor-alpha in the modulation of glucosestimulated insulin secretion. Diabetes 53 Suppl 1 S71-S81.

Tamashiro KL, Wakayama T, Akutsu H, Yamazaki Y, Lachey JL, Wortman MD, Seeley RJ, D'Alessio DA, Woods SC, Yanagimachi R \& Sakai RR 2002 Cloned mice have an obese phenotype not transmitted to their offspring. Nature Medicine 8 262-267.

Tokunaga C, Yoshino K \& Yonezawa K 2004 mTOR integrates amino acid- and energy-sensing pathways. Biochemical and Biophysical Research Communications 313 443-446.

Turner BM 2002 Cellular memory and the histone code. Cell 111 285-291.

van Bilsen $M$, van der Vusse GJ, Gilde AJ, Lindhout $M$ \& van der Lee KA 2002 Peroxisome proliferator-activated receptors: lipid binding proteins controling gene expression. Molecular and Cellular Biochemistry $239131-138$.

van der Sanden $\mathbf{M H}$, Meems H, Houweling M, Helms JB \& Vaandrager $\mathbf{A B} 2004$ Induction of CCAAT/enhancer-binding protein C/EBP-homologous protein/growth arrest and DNA damage-inducible protein 153 expression during inhibition of phosphatidylcholine synthesis is mediated via activation of a C/EBP-activating transcription factor-responsive element. Journal of Biological Chemistry 279 52007-52015.

Wang XZ, Kuroda M, Sok J, Batchvarova N, Kimmel R, Chung $P$, Zinszner H \& Ron D 1998 Identification of novel stress-induced genes downstream of chop. EMBO / 17 3619-3630.

Welm AL, Timchenko NA \& Darlington GJ 1999 C/EBPalpha regulates generation of C/EBPbeta isoforms through activation of specific proteolytic cleavage. Molecular and Cellular Biology 19 1695-1704.

Wolff GL, Kodell RL, Moore SR \& Cooney CA 1998 Maternal epigenetics and methyl supplements affect agouti gene expression in Avy/a mice. FASEB J 12 949-957.

Xu G, Kwon G, Cruz WS, Marshall CA \& McDaniel ML 2001 Metabolic regulation by leucine of translation initiation through the mTOR-signaling pathway by pancreatic beta-cells. Diabetes $\mathbf{5 0}$ $353-360$

Yajnik CS 2004 Early life origins of insulin resistance and type 2 diabetes in India and other Asian countries. Journal of Nutrition 134 205-210.

Yoshikawa T, Ide T, Shimano H, Yahagi N, Amemiya-Kudo $M$, Matsuzaka T, Yatoh S, Kitamine T, Okazaki H, Tamura Y, Sekiya M, Takahashi A, Hasty AH, Sato R, Sone H, Osuga Ji, Ishibashi S \& Yamada N 2003 Cross-Talk between Peroxisome Proliferator-Activated Receptor PPAR \{alpha\} and Liver X Receptor LXR in Nutritional Regulation of Fatty Acid Metabolism. I. PPARs Suppress Sterol Regulatory Element Binding Protein-1c Promoter through Inhibition of LXR Signaling. Molecular Endocrinology 17 1240-1254.

Yoshikawa T, Shimano H, Amemiya-Kudo M, Yahagi N, Hasty AH, Matsuzaka T, Okazaki H, Tamura Y, lizuka Y, Ohashi K, Osuga Ji, Harada K, Gotoda T, Kimura S, Ishibashi S \& Yamada N 2001 Identification of Liver $X$ Receptor-Retinoid $X$ Receptor as an Activator of the Sterol Regulatory Element-Binding Protein 1c Gene Promoter. Molecular and Cellular Biology 21 2991-3000. 
Young LE \& Beaujean N 2004 DNA methylation in the preimplantation embryo: the differing stories of the mouse and sheep. Animal Reproduction Science 82-83 61-78.

Young LE, Fernandes K, McEvoy TG, Butterwith SC, Gutierrez CG, Carolan C, Broadbent PJ, Robinson JJ, Wilmut I \& Sinclair KD 2001 Epigenetic change in IGF2R is associated with fetal overgrowth after sheep embryo culture. Nature Genetics 27 153-154.

Zhang K \& Kaufman RJ 2004 Signaling the Unfolded Protein Response from the Endoplasmic Reticulum. Journal of Biological Chemistry $27925935-25938$.

Zheng P, Patel B, McMenamin M, Moran E, Paprocki AM, Kihara M, Schramm RD \& Latham KE 2005 Effects of follicle size and oocyte maturation conditions on maternal messenger RNA regulation and gene expression in rhesus monkey oocytes and embryos. Biology of Reproduction 72 890-897.
Zhu MJ, Ford SP, Nathanielsz PW \& Du M 2004 Effect of maternal nutrient restriction in sheep on the development of fetal skeletal muscle. Biology of Reproduction 71 1968-1973.

Zile MH 2001 Function of vitamin A in vertebrate embryonic development. Journal of Nutrition 131 705-708.

Zinszner H, Kuroda M, Wang X, Batchvarova N, Lightfoot RT, Remotti H, Stevens JL \& Ron D 1998 CHOP is implicated in programmed cell death in response to impaired function of the endoplasmic reticulum. Genes \& Development 12 982-995.

Received 17 April 2005

First decision 3 May 2005

Revised manuscript received 7 July 2005

Accepted 5 August 2005 